\title{
THE CONTRIBUTION OF AMATEUR ASTRONOMERS TO ASTRONOMY EDUCATION
}

\author{
Cecylia Iwaniszewska \\ Institute of Astronomy, Nicolaus Copernicus University, Torun, Poland
}

I would like to dedicate this paper to the memory of my husband, Henryk Iwaniszewski, an astronomer working in radio astronomy and electronics, who until his untimely death seven years ago had been very active as president of our local branch of the Polish Amateur Astronomers Association. He was especially keen about introducing astronomy to the general public.

I want to speak here mainly, but not exclusively, about the IAU Colloquium No. 98, "Contribution of Amateur Astronomers to Astronomy," which was held in 1988 in Paris. First of all, some definitions. Thomas Williams of the American Association of Variable Star Observers (AAVSO), from Houston, Texas, introduced at the conference several criteria for identification - first of astronomers, and then of professionals and amateurs. According to Williams:

- astronomers must display a serious intent to contribute to the advancement of astronomy,

- they must produce results over an extended period of time,

- their work must be conducted using acceptable methods or techniques,

- the results obtained should be communicated to other astronomers.

The distinction between professionals and amateurs is as follows:

- a professional astronomer is a person who practices the science of astronomy for a livelihood with great skill,

- an amateur astronomer does astronomy for pleasure rather than for money, and derives his or her income from other means than astronomy.

A distinction should be made here also between amateurs and recreational sky observers, who, while appreciating the beauties of the night sky, are not motivated to use their time and skill to contribute to science.

Taking into account the above criteria, Thomas Williams produced a world list of amateurs, or amateurs who later became professionals, comprising nearly 700 names, from the mid-sixteenth century to the present. When looking over the astronomical interests of the persons on this list, I found out that in seventy cases, just ten per cent, the amateurs had been interested in education or popularization, although not exclusively. This was the past; what are the interests of present day amateurs?

At the Paris Colloquium, we saw that the amateurs' contribution to astronomy might be divided into three parts, directed towards three aims: 
- to astronomical observations, where they can contribute valuable data for further research work, and indeed they are a great help for professionals,

- to the past, the history of astronomy, where they show more patience in studying old documents and taking care of historical instruments and buildings,

- to the present and future, to the education of contemporary society and generations to come, introducing sometimes quite spectacular forms of popularization.

When listening for five days to the accounts of the activities of amateur astronomers, I began to wonder why they display much more enthusiasm than professionals?

Is it actually because, for this group, astronomical work is a hobby, and not work one has to do for one's salary?

Is it because amateurs usually work in local associations, ordinarily independent of teaching institutions, schools, universities, which may in turn have no institutional interests in popularization at large?

Or is it because of the equal status of every member in an amateur association, independent of their professional position and education but dependent only on their abilities and amount of work they want to spend on the association activities and projects?

I think that in smaller towns, communities, or even provinces, a local association of amateurs may act for the astronomical education of the general public in a way similar to the activity of a planetarium staff, whose tasks are not restricted exclusively to arranging sky-shows under the planetarium dome.

Here are some examples of the actions of amateurs towards raising the level of astronomical education in their respective countries, examples taken from different parts of the world.

My first case is a small, or medium-sized country, with two universities, no observatory, and only one professional astronomer. How can one improve the local astronomical knowledge? By taking advantage of special events, like the coming of Comet Halley, which happened to have in the southern hemisphere especially favorable observing conditions, and ... founding an amateurs' club. The members begin by taking photographs of the Comet; then become interested in other celestial bodies; then they want to know more, so they organize astronomical lectures and special courses; then they want to communicate with each other so they publish their own periodical, a trimestrial magazine, and run astronomical columns in daily newspapers and patronize TV programs. These people become the nucleus of astronomical activity aimed at reaching a higher level of astronomical education in the capital, in the whole country. The amateur group has been named "Club de Astrofísica del Paraguay."

It seems a pity that one cannot change the 76-year period to have Comet Halley visiting us more frequently, perhaps every 30 years, once in every generation?

In another, northern country, 7000 amateurs are members of some 30 amateur associations, the most important being the Ursa Astronomical Association. Ursa 
plays an important role in public education, publishing books, star maps, magazines, organizing Astronomy Days, etc. However, in my opinion, the most important step towards helping astronomy education in Finland has been the donation of wall star maps produced by the association to all, more than 5000 , schools in the country. In that way the teachers are obliged to learn some basic astronomy to be able to comment on the gift; that would be the least they can do. Or will the maps be carefully stored in school cupboards?

One must stress here the importance of the existence of small astronomy clubs in schools. They must of course gain some more experience, a longer tradition like, for instance, the Pleiades Club in Nice, France, founded more than twenty years ago. The Club activities, like observations, exhibitions, and travel to big observatories, were supplemented a few years ago by a project of active education: the construction of a school planetarium and observatory, a building of a sort of metal-grid covered by a concrete layer and situated in the school-yard. It took about four years of children's work during school-free days, sometimes also during vacations, to have the building ready. Now they are still working in the interior. In that way the club members acquired not only astronomical knowledge but also got to know about real hard work, work done collectively, work done for a group, for others who will learn in College Valeri in the future. And that is also education.

After hard work, people like to have some recreation, to take walks through parks or woods. Why not teach people some astronomy during their leisure time instead of in the classroom? The Swiss Amateur Association designed a set of SolarSystem Promenades. Taking the diameter of the Sun equal to $1.4 \mathrm{~m}$, and that of Mercury equal to $5 \mathrm{~mm}$, models of every planet in suitable size and distance were placed over a considerable area. Information about every planet is given next to the model. To reach Pluto from the Sun one has to stroll over $6 \mathrm{~km}$, and that is a fairly good walk.

Big cities have other problems: how to introduce some astronomy to a capital with much traffic, with people rushing all the time? How to reach large groups of people waiting for the next car, the next bus? In 1985, the year of Comet Halley, a group of young French amateurs arranged for astronomy presentations on the platforms of 16 stations of the Paris underground. For two weeks, they patiently explained exhibitions, commented on movies, answered questions. And, since in the end many millions of visitors attended the shows, I suppose this was one of the biggest popularization enterprises.

When talking of large groups of people one ought to mention amateur associations, who invite the public to their yearly conventions. It happens in Japan, where the twentieth anniversary of amateurs gathered 1000 visitors; in Venezuela at the tenth anniversary of amateurs; and at the Thai Astronomical Society meeting celebrating 300 years of Thai astronomy, since the first observations of the solar eclipse were made in 1688 by King Narai.

In the National Reports on Astronomy Education sent by the National Representatives to IAU Commission 46, I have read about amateur societies and their activities in nearly every country. Their work and help in popularization and edu- 
cation are everywhere deeply appreciated.

Now I would like to turn to a small country, my own country, to our Polish Amateur Astronomers Association, more than sixty years old, which publishes a monthly magazine, "Urania"; which has organized national seminars on teaching problems, taking together teachers and professionals; and which organizes various forms of activity for pupils and students. Our local Torun branch offers interested secondary-school students activities in a club conducted by two professional astronomers, outside their normal duties. During the school year, they meet every week at the Observatory; during vacations they have astronomical summer camps in the mountains or at the sea. During winter, our amateur branch organizes a series of lectures for the general public, where we try an interdisciplinary approach, to show the connection of astronomy with other sciences. The titles of lecture series of the past are as follows: Time in Nature, Energy, Visible and Invisible Light, Magnetic Fields in Nature, The Turbulent Universe, and Cosmic Chemistry, the lecturers being professional astronomers, or physicists, geologists, geophysicists, or even biologists, generally from our Torun University. The lectures take place in a modern, well equipped lecture room of the old, 14-16th century Town Hall of Torun, right in the middle of the old city, a few meters from the house where Nicolaus Copernicus was born 515 years ago.

And I would like in the end to mention another solar-system model, a model for the Torun audience. The idea of preparing models based on the local highest buildings, which I use in popular lectures, came from the paper of Rainer Gaitsch from the German Federal Republic presented at the Societá Astronomica Italiana conference in 1985. Taking then the 53-m tower of the old St. John's Church of Torun as the diameter of the Sun, we get a model in which the Earth is $51 \mathrm{~cm}$ and the Moon is $12 \mathrm{~cm}$, and all planetary orbits can be drawn on the map of Poland: the first in close vicinity to Torun, Neptune's orbit passing through our capital, Warsaw, and Pluto still farther out.

And then, let me end with the words describing the reason why amateurs are interested in the sky, the words of our Torun patron, Nicolaus Copernicus, from book I of De Revolutionibus: "... and what is there more beautiful than the HEAVENS, which indeed embrace everything that is lofty and beautiful?"

\section{Additional Comments}

C. Iwaniszewska:

1. Yesterday I received some comments about the name of Commission 46, and I see that in my talk I used the word "Education" - not "Teaching" as Prof. Sam Okoye has proposed. I think it could not be possible to change the name of the Commission, but indeed we think about education.

2. Since there has been some discussion about the introducing of astronomy as a separate subject, I would like to announce that in Poland a new subject has been introduced in secondary schools, "physics with astronomy," where astronomy has to be taught as another part of the subject, and not as something 
left over.

3. Looking over last evening's posters, I felt much moved by one of them, about introducing astronomy to the visually disabled. I think we usually do not remember about those who cannot see the beauties of the sky.

\section{Discussion}

A.E. Troche-Boggino: I am grateful to you for your mention of a club from my country, the Club de Astrofísica del Paraguay and its educational magazine Astrocosas. I am sure all its members are going to be pleased with what you have said of us.

J.-C. Pecker:

1. Even professional astronomers do work for the excitement of astronomy: if they had been looking for money, they would have selected some other occupation - banking, business...

2. The "Club des Pléiades" you mention as having built an observatory and a planetarium at school by themselves, spent only slightly more than $\$ 1000$ for the building. Any school can afford that small expense!

3. There is a serious need for some international link (union, federation, ...) among amateurs (individuals, clubs, associations, ...).

4. I do not believe that IAU Commissions 38 and 46 should merge: Commission 38 addresses "grown-up" qualified astronomers. Young astronomers need to travel, even after being educated or after getting their Ph.D.'s.

5. At school, should astronomy be taught as a part of some "physics and astrophysics" course, by a physicist? I doubt it: physicists have a tendency to describe astronomical problems as applications of physical questions (plasmas, spectra, solid state, thermodynamics); but then, one never sees the "unity" of the astronomical realm.

C. Iwaniszewska: Teachers must be suitably prepared but I still think it is better to have physicists instead of biologists, etc., doing astronomy teaching.

P. Moore: I was glad that the speaker referred to the popularization of astronomy for handicapped people. I am associated, unofficially but deeply, with handicapped children, and when I was recently at a school for blind children, I was asked to prepare a text that could be produced in Braille. It is not easy, but I hope that it can be done usefully. Also, I am sure that the speaker, like myself, always warns beginners about the dangers of observing the sun. In my view, direct observations of the sun with any telescope, with or without a dark filter, should always be avoided. 